\title{
Predicting the diagnosis of prostate cancer with a scoring system based on novel biomarkers
}

\author{
Durvesh Lachman Jethwani ${ }^{*}$, Lameena Lalitha Sivamoorthy ${ }^{2}$, Charng Chee Toh ${ }^{1}$ and Rohan Malek
}

\begin{abstract}
Objective: To predict prostate cancer using novel biomarker ratios and create a predictive scoring system.

Materials and methods: Data of a total of 703 patients who consulted Urology Department of Selayang Hospital between January 2013 and December 2017 and underwent prostate biopsy were screened retrospectively. Prostate specific antigen (PSA) levels, prostate volumes (PV), neutrophil and lymphocyte counts, neutrophil-to-lymphocyte ratio (NLR), Prostate specific antigen density (PSAD) and histopathology were evaluated.

Results: Ages ranged from 43 to 89 years, divided into 2 groups as per biopsy results; positive for prostate cancer ( $n=290,41.3 \%)$ and negative for malignancy $(n=413 ; 58.7 \%)$. Intergroup comparative evaluations were performed. Independent variables with $p<0.001$ in the univariate analysis were age, DRE, PV, NLR, PSAD. A scoring system was modelled using NLR $<0.9$, PSAD $>0.4$, Age $>70$ and DRE. A score of 2 or more predicted prostate cancer with a Sensitivity of $83.8 \%$ and Specificity of $86.4 \%$.
\end{abstract}

Conclusions: NLR is shown to be good predictor for prostate cancer its usage in this scoring system affords more disease specificity as compared to PSA alone.

Keywords: Prostate cancer, Novel biomarker ratios, Neutrophil-to-lymphocyte ratio, PSA density, TRUS biopsy

\section{Background}

Prostate cancer is the fifth most common cancer amongst the male population in Malaysia, with a lifetime risk of developing cancer being 1 in 117 [1]. Transrectal ultrasound guided biopsies (TRUS) remains the gold standard for diagnosing prostate cancer, though not without its own set of complications. The list of complications includes per rectal bleeding, hematuria, and sepsis. Prostate specific antigen (PSA) is a polypeptide that is expressed at very high levels in prostate epithelial cells that was first discovered in 1988. It has since been used widely as a screening tool for prostate cancer. However,

\footnotetext{
*Correspondence: DurveshJ@gmail.com

${ }^{1}$ Department of Urology, Hospital Selayang, Batu Caves, Selangor, Malaysia

Full list of author information is available at the end of the article
}

it lacks in disease specificity and can be raised in various other conditions including prostate inflammation and benign prostatic hyperplasia. This has led to many unnecessary biopsies. Hence, there is a necessity to develop other screening tools. There have been various studies comparing other markers including PSA derivatives and inflammatory parameters as an additional screening tool. In recent years, the role of inflammation in carcinogenesis and aggressiveness of the cancer has been studied in various types of cancer. A tissue microenvironment is created by inflammation via increased cell replication, angiogenesis, and tissue repair, which are all related to carcinogenesis. There has been more emphasis on inflammatory markers as a tool in not only diagnosing but also as a prognostic indicator for many cancers including lung, colorectal, pancreatic, ovarian, and prostate cancer. 
These markers include C-reactive protein (CRP), platelet counts, neutrophil counts, neutrophil-lymphocyte ratio (NLR), and platelet-lymphocyte ratio [2-6]. The rationale of this study is to improve the accuracy in detecting prostate cancer by using novel biomarker ratios. NLR, PV \& PSAD have not been used together for prediction of prostate cancer in previous studies. If validated, it may be a useful and inexpensive tool in predicting prostate cancer, thus reducing the number of unnecessary biopsies.

\section{Objective}

\section{General objective}

This study aims to evaluate the ability of novel biomarker ratios in predicting the diagnosis of prostate cancer.

\section{Specific objectives}

1. To determine the association between novel biomarker ratio (NLR to PV \& neutrophil count to PV \& NLR to PSAD) and prostate cancer

2. To determine the area under the curve, cut off values, sensitivity, and specificity for the above in predicting prostate cancer

3. To develop a scoring system between these biomarkers and other factors (e.g., age and abnormal DRE) to predict the diagnosis of prostate cancer

\section{Material and methodology}

This single center retrospective case-control study was approved by our institutional ethics review board and Medical Research Ethics Committee. All patients who underwent a TRUS biopsy from January 2013 to December 2017 were recruited. All data was analyzed anonymously. All men underwent TRUS prostate biopsies secondary to elevated PSA levels or abnormal digital rectal exams (DRE). In all men, the prostate was routinely biopsied bilaterally near the base, mid-gland region, and apex, taking at least six biopsies per side. The control group were those whose biopsies turned out negative for malignancy. Inclusion criteria were all patients who underwent a TRUS biopsy during the study duration and had a full blood count result within 6 months of the biopsy. Excluded from study were those who were previously diagnosed with prostate cancer, had previous prostate surgery as it may interfere to inaccurate volume calculation, previous or on-going treatment with 5- $\alpha$ reductase inhibitor (5-ARI), those with Full Blood Count (FBC) taken during an acute illness (e.g., respiratory tract infection, fever), those who were on immunosuppressants such as steroids, and PSA taken while on catheter or suffering from prostatitis. Out of 1997 patients that underwent TRUS biopsies in the stipulated time, 703 patients met the requirements, of which 290 were diagnosed with prostate cancer and 413 had biopsied that returned negative for malignancy. A methodology flowchart is illustrated in Fig. 1.

\section{Study protocol}

Electronic medical records of the study population were examined to retrieve the data needed. Our standard protocol for transrectal prostate biopsy is the 12-quadrant template biopsy with local anesthesia after receiving preoperative administration of antibiotic prophylaxis and distal bowel preparation. Biopsy specimens were evaluated in the same histopathology clinic. PSA levels and prebiopsy whole blood cell counts were obtained from the hospital laboratory. Prostate volume was determined via measurements taken on TRUS. PSA density was calculated by dividing the serum PSA level by the prostate volume on TRUS (maximum longitudinal diameter $x$ maximum transverse diameter $\times$ maximum AP diameter $\times \pi / 6)$. NLR was calculated as the absolute neutrophil count divided by the absolute lymphocyte count taken from full blood count results.

\section{Data analysis}

Data analysis was performed using SPSS version IBM 23.0. Descriptive analysis was conducted for each variable. A univariate analysis followed by a multivariate regression determined the association between each variable and the novel biomarkers with prostate cancer within the study population. We determined the cut-off point according to the sensitivity and specificity levels derived from area under curve (AUC) for receiver operator characteristics (ROC) curve plotted using the presence or absence of prostatic cancer with Youden Index formula. A scoring system was created using the significant variables. The predictive accuracy (sensitivity \& specificity) of the scoring system was assessed using receiver operating characteristic (ROC)-derived area under the curve (AUC) analysis.

\section{Results}

The data of the 703 included patients is displayed in displayed in Table 1 . Just over sixty four percent of the patients (186 patients) were diagnosed with clinically significant prostate cancer (Gleason score $\geq 7$ ). The average age (69 \pm 7 years) of patients with prostate cancer was older than those without cancer ( $66 \pm 6.5$ years). Based on the logistic regression analysis, with an increase in age there was a positive association in developing prostate cancer, with an odds ratio of 1.072 (95\% CI 1.047-1.097, $p<0.001)$. Majority of patients were of Malay origin (138 patients with prostate cancer and 233 patients with negative biopsy results). Followed by Chinese ethnicity; 
1997 patients under Urology

Selayang follow up who

underwent TRUS biopsies

703 patients who met the inclusion \& exclusion criteria were enrolled in the study

290 with TRUS biopsy results came back with prostate cancer
413 patients with TRUS biopsy results came back as non malignant

Fig. 1 Methodology flowchart

accounting for $122(42.1 \%)$ patients with prostate cancer and $146(35.4 \%)$ patients without prostate cancer, then Indians; 27 (9.3\%) with prostate cancer and $32(7.7 \%)$ without cancer. This reflected the local demography of the population.

Approximately $50-53.5 \%$ of patients had hypertension, $20-25 \%$ had diabetes, $3.1-4.8 \%$ had chronic kidney disease and $10 \%$ had heart disease. None of these illnesses appear to influence the rate of prostate cancer. Patients with abnormal digital rectal examination (DRE) were $56.2 \%$ more likely to have prostate cancer $(p<0.001)$. Prostate volumes were smaller in the prostate cancer arm $46.8 \pm 30.4 \mathrm{mls}$ as opposed to the control arm $57.8 \pm 29.4 \mathrm{mls}(p<0.001)$.

Next, we conducted univariate analysis of all the blood parameters and biomarker ratios, and neutrophil count was comparable between both groups. However, both lymphocyte and NLR showed a significant difference between the two groups. Both PSA and PSAD were higher in the prostate cancer arm; mean 238.15 $( \pm 640.98)$ and $6.48( \pm 21.89)$ respectively versus 11.93 $( \pm 14.00)$ and $0.27( \pm 1.08)$. NLR: PV and NLR: PSAD were lower in prostate cancer; 0.035 ( \pm 0.109) versus $0.115( \pm 0.207)$ and $10.03( \pm 68.96)$ versus 42.19 
Table 1 Characteristics and blood parameters of patients with biopsy results positive for prostate cancer and negative for malignancy

\begin{tabular}{|c|c|c|c|c|c|c|c|c|}
\hline \multirow{2}{*}{$\begin{array}{l}\text { Patient } \\
\text { characteristics }\end{array}$} & \multirow{2}{*}{$\begin{array}{l}\text { Prostate cancer/ } \\
\text { positive biopsy }\end{array}$} & \multirow{2}{*}{$\begin{array}{l}\text { Non malignant/ } \\
\text { negative biopsy }\end{array}$} & \multicolumn{3}{|c|}{ Univariate analysis } & \multicolumn{3}{|c|}{ Multivariate analysis } \\
\hline & & & Odds Ratio & $\begin{array}{l}95 \% \\
\text { Confidence } \\
\text { Interval }\end{array}$ & $\begin{array}{l}\text { Significance } \\
p \text { value }\end{array}$ & $\begin{array}{l}\text { Adjusted } \\
\text { Odds } \\
\text { Ratio }\end{array}$ & $\begin{array}{l}95 \% \\
\text { Confidence } \\
\text { Interval }\end{array}$ & $\begin{array}{l}\text { Significance } \\
p \text { value }\end{array}$ \\
\hline \multicolumn{9}{|c|}{$P C a(\%)$} \\
\hline $\begin{array}{l}\text { Gleason ?3+4 (ISUP } \\
1,2)\end{array}$ & $104(35.9 \%)$ & - & - & - & - & - & - & - \\
\hline \multirow[t]{2}{*}{$\begin{array}{l}\text { Gleason } ? 4+3 \text { (ISUP } \\
3,4,5)\end{array}$} & & - & & & & & & \\
\hline & $186(64.1 \%)$ & & & & & & & \\
\hline Age (years) & & & 1.072 & $1.047-1.097$ & $<0.001$ & 1.093 & $1.054-1.134$ & $<0.001$ \\
\hline Mean $( \pm S D)$ & $69( \pm 7.0)$ & $66( \pm 6.5)$ & & & & & & \\
\hline Median & 70 & 66 & & & & & & \\
\hline Range & $43-86$ & $46-89$ & & & & & & \\
\hline \multicolumn{9}{|l|}{ Ethnicity (\%) } \\
\hline Malay & $138(47.6)$ & $233(56.4)$ & 1 & & 0.127 & & & \\
\hline Chinese & $122(42.1)$ & $146(35.4)$ & 0.395 & $0.065-2.392$ & 0.312 & - & - & - \\
\hline Indian & $27(9.3)$ & $32(7.7)$ & 0.557 & $0.092-3.388$ & 0.525 & & & \\
\hline Others & $3(1.0)$ & $2(0.5)$ & 0.563 & $0.087-3.617$ & 0.545 & & & \\
\hline \multicolumn{9}{|l|}{ Hypertension } \\
\hline No & $145(50.0)$ & $221(53.5)$ & 1 & & & - & - & - \\
\hline Yes & $145(50.0)$ & $192(46.5)$ & 1.151 & $0.852-1.555$ & 0.359 & & & \\
\hline \multicolumn{9}{|l|}{ Diabetes } \\
\hline No & $215(74.1)$ & $325(78.7)$ & 1 & & & - & - & - \\
\hline Yes & $75(25.9)$ & $88(21.3)$ & 1.288 & $0.905-1.834$ & 0.159 & & & \\
\hline \multicolumn{9}{|l|}{ Chronic kidney disease } \\
\hline No & $281(96.9)$ & $393(95.2)$ & 1 & & & - & - & - \\
\hline Yes & $9(3.1)$ & $20(4.8)$ & 0.629 & $0.282-1.403$ & 0.257 & & & \\
\hline Heart disease & & & & & & & & - \\
\hline No & $260(89.7)$ & $371(89.8)$ & 1 & & & - & - & \\
\hline Yes & $30(10.3)$ & $42(10.2)$ & 1.019 & $0.622-1.671$ & 0.94 & & & \\
\hline \multicolumn{9}{|l|}{ DRE (\%) } \\
\hline Normal & $177(61.0 \%)$ & $304(73.6 \%)$ & 1 & & & & & \\
\hline Abnormal & $113(39.0 \%)$ & 109 (26.4\%) & 1.562 & $1.407-1.775$ & $<0.001$ & 0.848 & $0.511-1.408$ & 0.525 \\
\hline $\begin{array}{l}\text { Prostate volume/ } \\
\text { PV }(g)\end{array}$ & & & 0.986 & $0.980-0.992$ & $<0.001$ & 0.971 & $0.962-9.982$ & $<0.001$ \\
\hline Mean $( \pm S D)$ & $46.8( \pm 30.4)$ & $57.8( \pm 29.4)$ & & & & & & \\
\hline Median & 40 & 51.3 & & & & & & \\
\hline Range & $10.0-287.0$ & $10.0-200.0$ & & & & & & \\
\hline $\begin{array}{l}\text { Neutrophil count } \\
\left(\times 10^{9}\right)\end{array}$ & & & 0.996 & $0.979-1.013$ & 0.616 & & & \\
\hline Mean $( \pm S D)$ & $8.04( \pm 8.57)$ & $8.38( \pm 9.36)$ & & & & & & \\
\hline Median & 5 & 5 & & & & - & - & - \\
\hline Range & $0.40-50.60$ & $1.60-87.10$ & & & & & & \\
\hline $\begin{array}{l}\text { Lymphocyte count } \\
\left(\times 10^{9}\right)\end{array}$ & & & 9.249 & $5.289-16.175$ & $<0.001$ & & & \\
\hline Mean & $22.86(11.2)$ & $2.01(0.72)$ & & & & & & \\
\hline Median & 24.43 & 1.9 & & & & - & - & - \\
\hline Range & $1.90-54.35$ & $0.30-5.10$ & & & & & & \\
\hline$N L R$ & & & 0.61 & $0.543-0.684$ & $<0.001$ & & & \\
\hline Mean $( \pm S D)$ & $1.15( \pm 2.80)$ & $4.91( \pm 6.47)$ & & & & & & \\
\hline
\end{tabular}


Table 1 (continued)

\begin{tabular}{|c|c|c|c|c|c|c|c|c|}
\hline \multirow{2}{*}{$\begin{array}{l}\text { Patient } \\
\text { characteristics }\end{array}$} & \multirow{2}{*}{$\begin{array}{l}\text { Prostate cancer/ } \\
\text { positive biopsy }\end{array}$} & \multirow{2}{*}{$\begin{array}{l}\text { Non malignant/ } \\
\text { negative biopsy }\end{array}$} & \multicolumn{3}{|c|}{ Univariate analysis } & \multicolumn{3}{|c|}{ Multivariate analysis } \\
\hline & & & Odds Ratio & $\begin{array}{l}95 \% \\
\text { Confidence } \\
\text { Interval }\end{array}$ & $\begin{array}{l}\text { Significance } \\
p \text { value }\end{array}$ & $\begin{array}{l}\text { Adjusted } \\
\text { Odds } \\
\text { Ratio }\end{array}$ & $\begin{array}{l}95 \% \\
\text { Confidence } \\
\text { Interval }\end{array}$ & $\begin{array}{l}\text { Significance } \\
p \text { value }\end{array}$ \\
\hline Median & 0.2 & 2.53 & & & & - & - & - \\
\hline Range & $0.03-20.67$ & $0.79-87.1$ & & & & & & \\
\hline PSA (ng/ml) & & & 1.051 & $1.039-1.063$ & $<0.001$ & - & - & - \\
\hline Mean $( \pm S D)$ & $238.15( \pm 640.98)$ & $11.93( \pm 14.00)$ & & & & & & \\
\hline Median & 47.18 & 8.6 & & & & & & \\
\hline Range & $0.06-5877.99$ & $0.34-191.61$ & & & & & & \\
\hline$P S A D(n g / m l / g)$ & & & 5.977 & $3.953-9.036$ & $<0.001$ & & & \\
\hline Mean $( \pm S D)$ & $6.48( \pm 21.89)$ & $0.27( \pm 1.08)$ & & & & & & \\
\hline Median & 1.05 & 0.17 & & & & - & - & - \\
\hline Range & $0.01-273.90$ & $0.01-21.74$ & & & & & & \\
\hline$N L R: P V$ & & & $1 E-04$ & $0.000-0.002$ & $<0.001$ & & & \\
\hline Mean $( \pm S D)$ & $0.035( \pm 0.109)$ & $0.115( \pm 0.207)$ & & & & & & \\
\hline Median & 0.006 & 0.052 & & & & - & - & - \\
\hline Range & $0.001-1.254$ & $0.005-2.524$ & & & & & & \\
\hline Neut:PV & & & 1.483 & $0.920-2.392$ & 0.106 & & & \\
\hline Mean $( \pm S D)$ & $0.235( \pm 0.341)$ & $0.194( \pm 0.312)$ & & & & & & \\
\hline Median & 0.133 & 0.1 & & & & - & - & - \\
\hline Range & $0.016-2.885$ & $0.015-4.291$ & & & & & & \\
\hline NLR:PSAD & & & 0.977 & $0.968-0.985$ & $<0.001$ & 1.004 & $1.002-1.006$ & $<0.001$ \\
\hline Mean $( \pm S D)$ & $10.03( \pm 68.96)$ & $42.19( \pm 112.21)$ & & & & & & \\
\hline Median & 0.22 & 16.94 & & & & & & \\
\hline Range & $0.001-754.55$ & $0.21-1907.30$ & & & & & & \\
\hline
\end{tabular}

$( \pm 112.21)$ respectively $(p<0.001)$. The plotted curves are seen in Fig. 2.

Independent variables with $p<0.001$ in the univariate analysis (age, DRE, PV \& NLR: PSAD) were selected for multivariate logistic regression. Lymphocyte count, PSA, PSAD \& NLR: PV were excluded for multicollinearity issue. A ROC curve as seen in Fig. 3 was plotted using the predictive probability. The ROC curve generated had an AUC of $0.903(p<0.001,95 \%$ CI 0.909-0.950) with sensitivity of $87.9 \%$ and $87.7 \%$.

Following which we conducted ROC curve analysis for the significant clinical parameters and biomarkers as per Table 2. The AUC for NLR was 0.901 with cut off value 0.904 had a sensitivity of $82.8 \%$ and specificity of 99.8 $(p<0.001)$. PSA and PSAD had near comparable values with AUC 0.813 and 0.849 respectively with low sensitivity $60.0 \%$ and $73.1 \%$ but high specificity of $94.7 \%$ and 89.3\%. As seen in Fig. 4, NLR: PSAD was a significant biomarker ratio with AUC of 0.946 , sensitivity of $85.5 \%$, specificity of $96.9 \%$.

A scoring system to predict the probability of having prostate cancer among patients was proposed, as seen in Table 3. It is composed of 4 clinical parameters: age, abnormal DRE, NLR and PSAD. A cut off value of $\geq 2$, places the patient at a higher risk of having prostate cancer. The generated ROC curve is seen in Fig. 5. By using the score of 2 as a cut off value, the model had a sensitivity of $83.8 \%$ and specificity of $86.4 \%$ in predicting prostate cancer.

\section{Discussion}

Most prostate cancer patients are asymptomatic as it is indolent unlike other cancers. Those with low-risk disease as per the D'Amico criteria, may not require radical therapy. Therefore, there has been a shift in the treatment paradigm, from diagnosing all cancers, to differentiating clinically significant prostate cancer to prevent over treatment or under treatment of the disease.

In our study we created a scoring system that was designed to be simple and easily applicable in the clinic setting. There are only 4 components: age, abnormal DRE findings, NLR and the PSAD. An ROC curve was plot and yielded promising results, with an AUC for clinically significant cancer $(G S \geq 7)$ of $91.5 \%$ (95\% CI 0.89-0.93). From this ROC curve, we determined that patients with a 

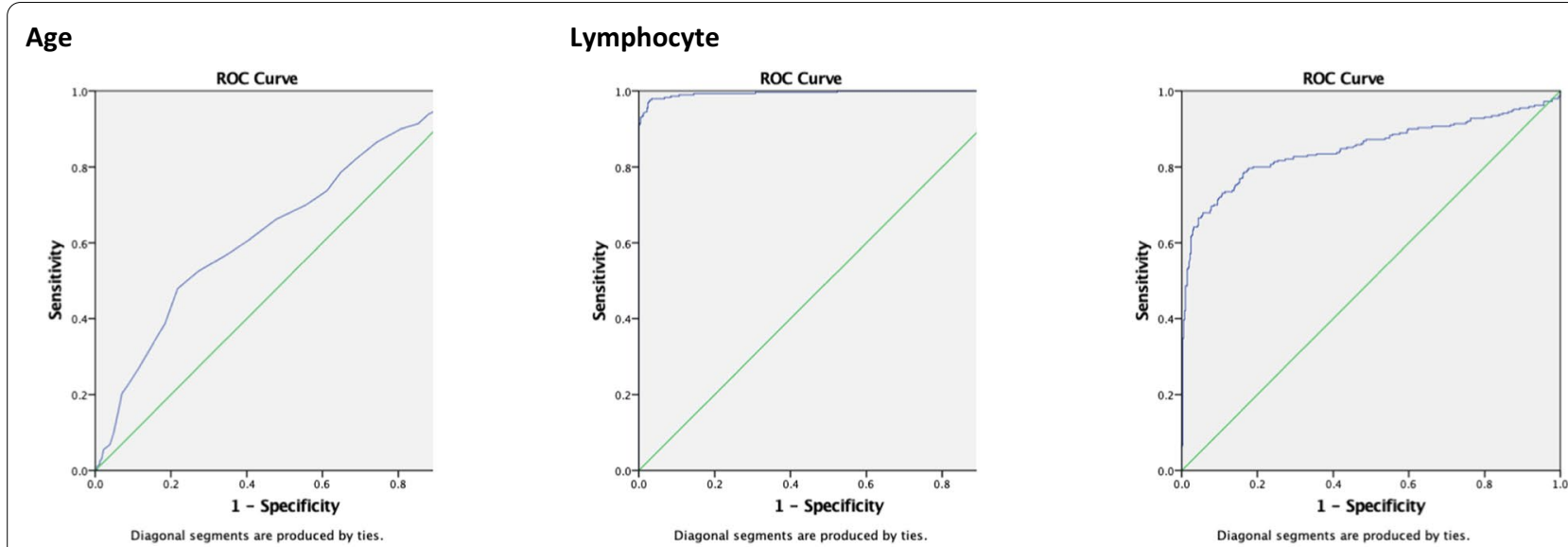

DRE

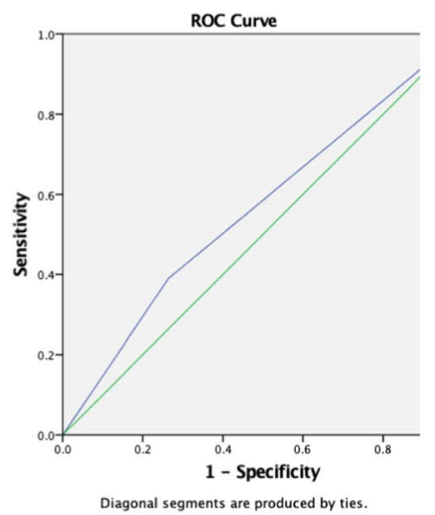

NLR

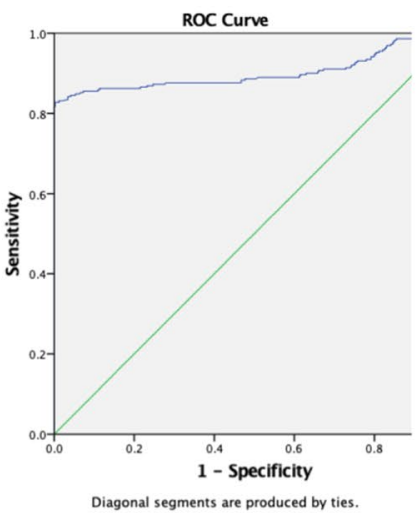

PSA

\section{Prostate Volume}
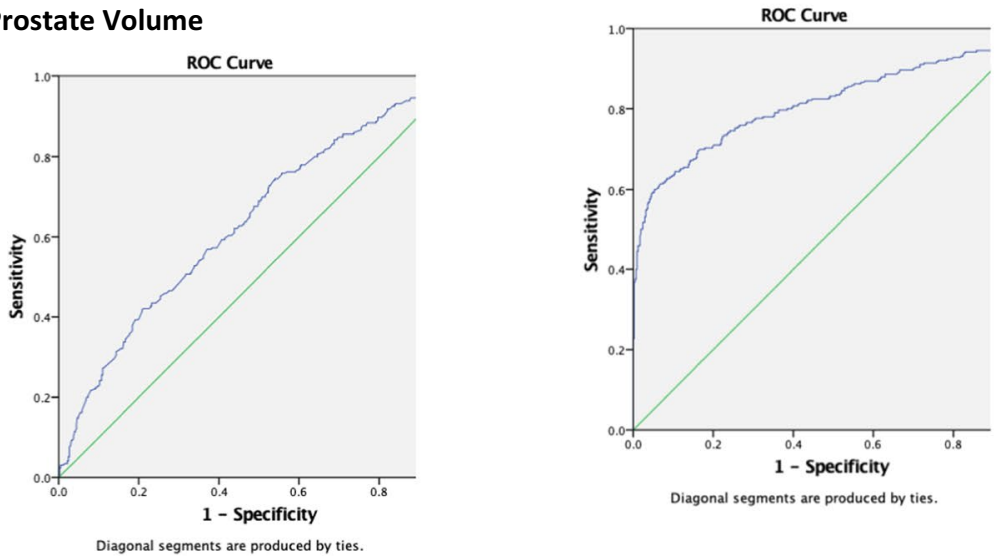

Fig. 2 ROC curves for significant variables

score of 2, likely had clinically significant prostate cancer with a sensitivity of $83.8 \%$ and specificity of $86.4 \%$.

Two of the more popular scoring systems that have been validated are the Prostate Cancer Prevention Trial Risk Calculator 2.0 (PCPT RC) and the newer Prostate Biopsy Collaborative Group (PBCG) Risk Calculator.
Ankerst et al. derived a median AUC of $74.4 \%$ (range 62.1-88.1) when designing the Second version of the (PCPT RC) [7]. Similarly, the PBCG calculator achieved an AUC of $75.5 \%$ (95\% confidence interval 74.2-76.8) in their cohorts [8]. 


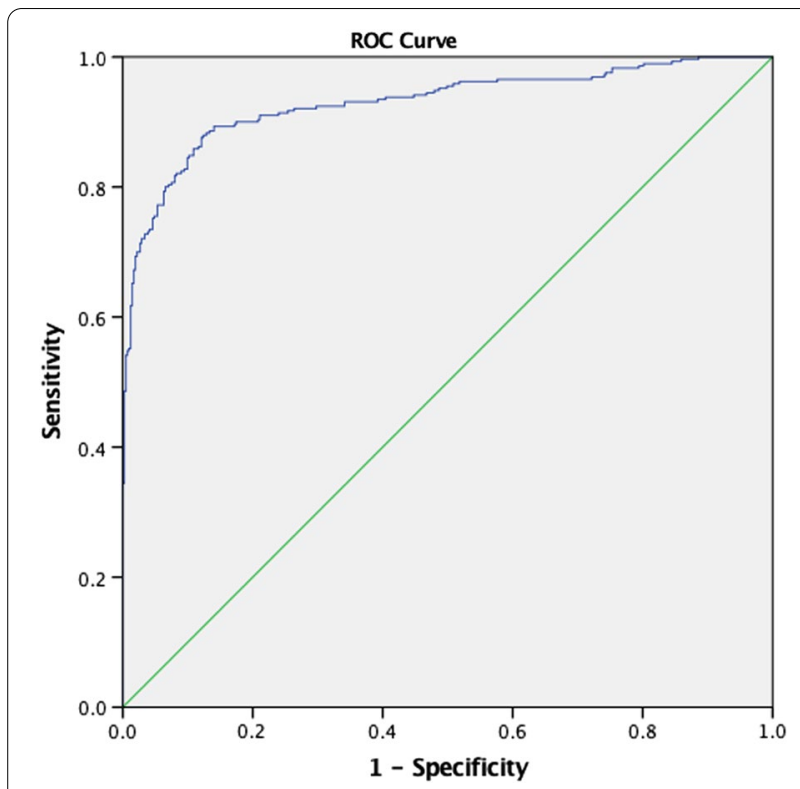

Fig. 3 ROC curve for multivariate regression

One of the key features of our scoring system was the inclusion of NLR, a novel biomarker. Toriola et al., Kawahara et al. and $\mathrm{Oh}$ et al. reported that pre-diagnostic inflammatory markers had a significant positive association with prostate cancer [9-11]. NLR has been shown to be associated with more aggressive disease and higher GS $[12,13]$. In our study we found at a cut off less than 0.9 , it had an AUC of $90 \%$ for clinically significant prostate cancer. NLR is a systemic inflammatory marker that has the advantage of being readily available, convenient, and cost effective.

Carbunaru et al. explored the effectiveness of these calculators in a multi-ethnic cohort and found the AUC for clinically significant Prostate Cancer was lower than the originally published articles at $64 \%$ (95\% CI $0.61-0.68$ ) for PCPT and 65\% (95\% CI 0.62-0.68) for PBCG [14]. A limiting factor of using these more established scoring systems, is that they may not reflect the Asian population. In the same study, the authors found that PBCG's calculator potentially biases a greater number of low-risk African American and other men towards unnecessary biopsies. The need for more data on Asian patients is highlighted by a study by Lim et al. conducted in Malaysia, which found that baseline PSA levels significantly vary amongst different ethnicities [15]. We were able to achieve a good AUC in our study cohort, which fairly reflected the multi-ethnicity of our Malaysian population.

The 2021 edition of the European Association of Urology practice guidelines advocates the use of either risk calculators or imaging (typically in the form of Multiparametric Magnetic Resonance Imaging (MP-MRI)), in asymptomatic men with a PSA $<10 \mathrm{ng} / \mathrm{mL}$ [16].

In the PROMIS study, Ahmed et al. found that the usage of a pre-biopsy MP-MRI was highly sensitive (93\%) in picking up clinically significant prostate cancer, resulting in the ability to exclude a patient from a biopsy if the result was negative, but with a poor specificity (41\%) there were still many patients undergoing biopsies with negative results [17].

To be of good value, MP-MRIs need to adhere to the Prostate Imaging Reporting \& Data System (PI-RADS) guidelines for acquisition and interpretation. This requires a significant level of expertise from a trained Radiologist. Paired with the hefty costs of purchasing and maintaining an MRI, there are only a limited number of centers which can cater to timely Pre-biopsy MP-MRIs. Though our scoring system, which excluded the usage of MP-MRIs, resulted in a lower sensitivity, the combination

Table 2 ROC curve analysis of variables

\begin{tabular}{llllllrr}
\hline & AUC & Cut off & $\begin{array}{l}\text { Sensitivity } \\
\text { Sn }\end{array}$ & $\begin{array}{l}\text { Specificity } \\
\text { Sp }\end{array}$ & Youden Index & $\begin{array}{l}\text { 95\% Confidence } \\
\text { Interval }\end{array}$ & $\begin{array}{l}\text { Significance } \\
\boldsymbol{p} \text { value }\end{array}$ \\
\hline Age & 0.640 & 70.5 & 47.9 & 78.2 & 0.261 & $0.598-0.682$ & $<0.001$ \\
DRE & 0.563 & - & 39.0 & 73.6 & - & $0.520-0.600$ & 0.005 \\
Prostate volume & 0.638 & 35.35 & 42.1 & 78.9 & 0.21 & $0.596-0.680$ & $<0.001$ \\
Lymphocyte & 0.995 & 3.50 & 97.6 & 97.1 & 0.947 & $0.990-0.999$ & $<0.001$ \\
NLR & 0.901 & 0.904 & 82.8 & 99.8 & 0.825 & $0.871-0.930$ & $<0.001$ \\
PSA & 0.813 & 27.54 & 60.0 & 94.7 & 0.577 & $0.778-0.849$ & $<0.001$ \\
PSAD & 0.849 & 0.409 & 73.1 & 89.3 & 0.624 & $0.815-0.882$ & $<0.001$ \\
Neut: PV & 0.579 & 0.108 & 63.4 & 54.3 & 0.182 & $0.536-0.621$ & $<0.001$ \\
NLR: PV & 0.881 & 0.126 & 75.5 & 98.5 & 0.741 & $0.850-0.913$ & $<0.001$ \\
NLR: PSAD & 0.946 & 3.303 & 85.5 & 96.9 & 0.824 & $0.926-0.967$ & $<0.001$ \\
Multivariate regression & 0.930 & - & 87.9 & 87.7 & - & $0.909-0.950<$ & $<0.001$ \\
Scoring system & 0.915 & 2 & 83.8 & 86.4 & 0.702 & $0.895-0.936<<<0.001$ & $<$
\end{tabular}




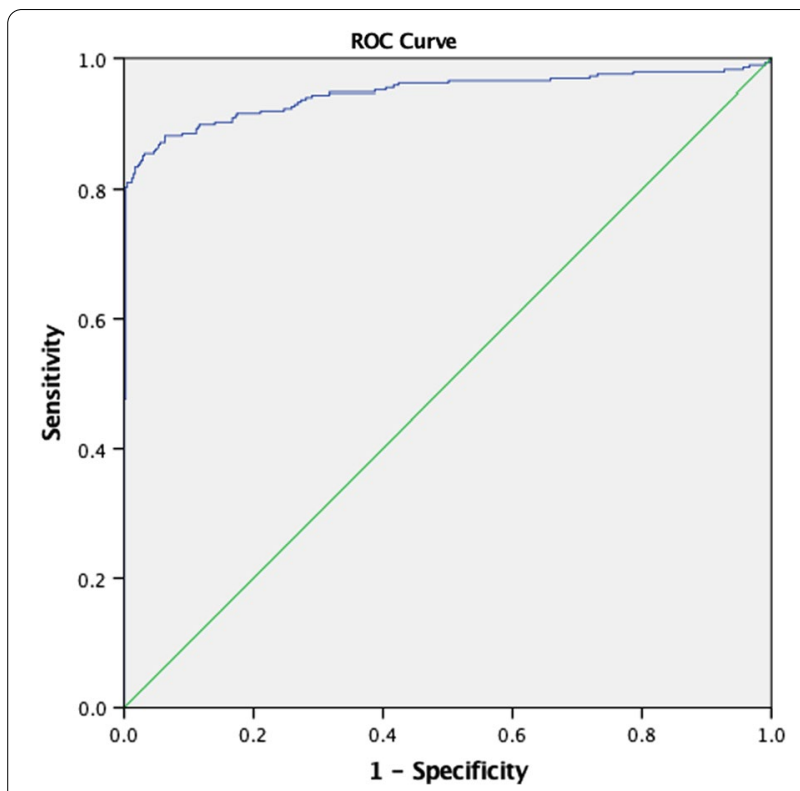

Fig. 4 ROC curve for NLR:PSAD

Table 3 Scoring system

\begin{tabular}{ll}
\hline Clinical factors & Score \\
\hline Age $>$ 70 & 1 \\
Abnormal DRE & 1 \\
NLR $<0.9$ & 1 \\
PSAD $>0.4$ & 1 \\
Total & 4 \\
\hline
\end{tabular}

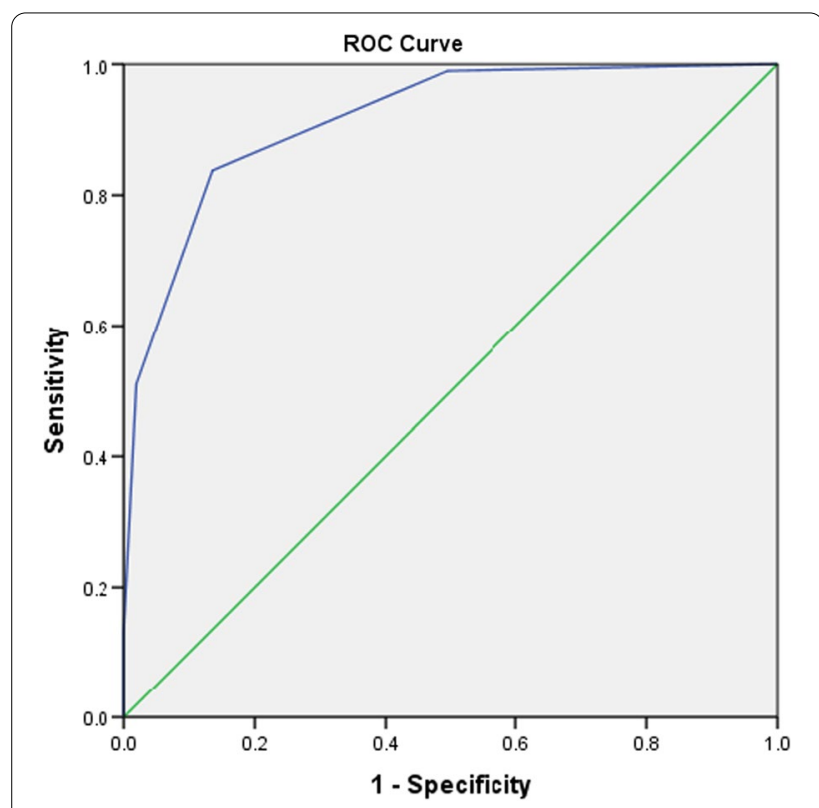

Fig. 5 ROC curve for scoring system of both Sensitivity and Specificity above $80 \%$ makes it a useful tool when counselling a patient about the possible outcomes from a biopsy.

Our study has several limiting factors. One of the main drawbacks of our study is its retrospective nature. Hence, information bias and selection bias could not be avoided. Follow up was not an integral part of our study. We only used data from a single center but we were able to get a good sample size, which represented our local Malaysian population. We also could not use other inflammatory markers such as CRP or procalcitonin to exclude patients with ongoing infection. We acknowledge the need for a prospective validation study to further determine the accuracy of these novel biomarker ratios and scoring system.

Another feature of our scoring system, PSAD, was achieved by measurement of the prostate volume via transrectal ultrasound, which is cumbersome to reproduce, especially if one has not committed to undertaking a biopsy.

\section{Conclusion}

In conclusion, with a higher sensitivity and specificity than DRE or elevated PSA alone, we believe usage of our scoring system could potentially reduce the number of unnecessary TRUS biopsies, which, in turn, will reduce the risk of complications to patients and reduce the burden to the healthcare system. We recommend this scoring system should be used to facilitate the counselling of a patient being considered for a biopsy. However, we acknowledge that prospective studies are needed to validate this.

\section{Abbreviations}

PSA: Prostate Specific Antigen; PV: Prostate Volume; DRE: Digital Rectal Examination; PSAD: Prostate Specific Antigen Density; NLR: Neutrophil to Lymphocyte Ratio; TRUS: Transrectal Ultrasound; AUC: Area Under Curve; ROC: Receiver Operator Characteristics; Cl: Confidence Interval; SD: Standard Deviation; SP: Specificity; SN: Sensitivity; FBC: Full Blood Count; MP-MRI: Multiplanar Magnetic Resonance Imaging; PI-RADS: Prostate Imaging Reporting and Data System; GS: Gleason Score.

\section{Authors' contributions}

All authors read and approved the final manuscript. DLJ and LLS collected, analyzed, and interpreted the data. DLJ was responsible for writing of manuscript. CCT and RM were supervising consultants who oversaw the process and provided invaluable feedback throughout the process of manuscript authorship.

\section{Funding}

The study was self-funded by the Corresponding author.

\section{Availability of data and materials}

The datasets used and/or analyzed during the current study are available from the corresponding author on reasonable request. 


\section{Declarations}

\section{Ethics approval and consent to participate}

The study was performed in accordance with the Declaration of Helsink and ethics approval was granted by the Medical Research Ethics Committee (MREC) of the Ministry of Health of Malaysia. The study is registered with the National Medical Research Register (NMRR) of the Ministry of Health of Malaysia with the following registration number: NMRR-18-363-39615. Informed consent was obtained from all subjects and/or their legal guardian(s).

\section{Consent for publication}

All authors have given consent to publication of this manuscript.

\section{Competing interests}

The authors declare that they have no competing interests.

\section{Author details}

1 Department of Urology, Hospital Selayang, Batu Caves, Selangor, Malaysia

${ }^{2}$ Department of General Surgery, Hospital Selayang, Batu Caves, Selangor, Malaysia.

Received: 30 August 2021 Accepted: 12 January 2022 Published online: 02 February 2022

\section{References}

1. Malaysia National Cancer Registry Report 2007-2011. http://www.care. upm.edu.my/dokumen/13603_NCR2007.pdf. Accessed 07 Sept 2020

2. Langsenlehner T, Thurner EM, Krenn-Pilko S, et al. Validation of the neutrophil-to-lymphocyte ratio as a prognostic factor in a cohort of European prostate cancer patients. World J Urol. 2015;33:1661-7. https://doi.org/10. 1007/s00345-015-1494-7.

3. Nuhn P, Vaghasia AM, Goyal J, Zhou XC, Carducci MA, Eisenberger MA, Antonarakis ES. NLR predicts OS in men with $\mathrm{MCRPC}$ receiving docetaxel. BJU Int. 2014;114:E11-7. https://doi.org/10.1111/bju.12531.

4. Templeton AJ, McNamara MG, Šeruga B, Vera-Badillo FE, Aneja P, Ocaña A, Leibowitz-Amit R, Sonpavde G, Knox JJ, Tran B, Tannock IF, Amir E. Prognostic role of neutrophil-to-lymphocyte ratio in solid tumors: a systematic review and meta-analysis. J Natl Cancer Inst. 2014;106(6):dju124. https://doi.org/10.1093/jnci/dju124.

5. Guthrie GJ, Charles KA, Roxburgh CS, Horgan PG, McMillan DC, Clarke SJ. The systemic inflammation-based neutrophil-lymphocyte ratio: experience in patients with cancer. Crit Rev Oncol Hematol. 2013;88(1):218-30. https://doi.org/10.1016/j.critrevonc.2013.03.010.

6. Buergy D, Wenz F, Groden C, Brockmann MA. Tumor-platelet interaction in solid tumors. Int J Cancer. 2012;130(12):2747-60. https://doi.org/10 1002/ijc.27441.

7. Ankerst DP, Hoefler J, Bock S, Goodman PJ, Vickers A, Hernandez J, Sokoll LJ, Sanda MG, Wei JT, Leach RJ, Thompson IM. Prostate Cancer Prevention Trial risk calculator 2.0 for the prediction of low- vs high-grade prostate cancer. Urology. 2014;83(6):1362-7. https://doi.org/10.1016/j.urology. 2014.02.035.

8. Ankerst DP, Straubinger J, Selig K, Guerrios L, De Hoedt A, Hernandez J, Liss MA, Leach RJ, Freedland SJ, Kattan MW, Nam R, Haese A, Montorsi F, Boorjian SA, Cooperberg MR, Poyet C, Vertosick E, Vickers AJ. A contemporary prostate biopsy risk calculator based on multiple heterogeneous cohorts. Eur Urol. 2018;74(2):197-203. https://doi.org/10.1016/j.eururo. 2018.05.003.

9. Toriola AT, Laukkanen JA, Kurl S, Nyyssönen K, Ronkainen K, Kauhanen J. Prediagnostic circulating markers of inflammation and risk of prostate cancer. Int J Cancer. 2013;133(12):2961-7. https://doi.org/10.1002/ijc. 28313.

10. Oh JJ, Kwon O, Lee JK, Byun SS, Lee SE, Lee S, Hong SK. Association of the neutrophil-to-lymphocyte ratio and prostate cancer detection rates in patients via contemporary multi-core prostate biopsy. Asian J Androl. 2016;18(6):937-41. https://doi.org/10.4103/1008-682X.164198.

11. Kawahara T, Fukui S, Sakamaki K, Ito Y, Ito H, Kobayashi N, Izumi K, Yokomizo Y, Miyoshi Y, Makiyama K, Nakaigawa N, Yamanaka T, Yao M, Miyamoto H, Uemura H. Neutrophil-to-lymphocyte ratio predicts prostatic carcinoma in men undergoing needle biopsy. Oncotarget. 2015;6(31):32169-76. https://doi.org/10.18632/oncotarget.5081.

12. Wang H, Gu L, Wu Y, et al. The values of neutrophil-lymphocyte ratio and/ or prostate-specific antigen in discriminating real Gleason score $\geq 7$ prostate cancer from group of biopsy-based Gleason score $\leq 6$. BMC Cancer. 2017;17:629. https://doi.org/10.1186/s12885-017-3614-9.

13. Gokce MI, Tangal S, Hamidi N, Suer E, Ibis MA, Beduk Y. Role of neutrophilto-lymphocyte ratio in prediction of Gleason score upgrading and disease upstaging in low-risk prostate cancer patients eligible for active surveillance. Can Urol Assoc J. 2016;10(11-12):E383-7. https://doi.org/10. 5489/cuaj.3550

14. Carbunaru S, Nettey OS, Gogana P, et al. A comparative effectiveness analysis of the PBCG vs. PCPT risks calculators in a multi-ethnic cohort. BMC Urol. 2019;19:121. https://doi.org/10.1186/s12894-019-0553-6.

15. Lim J, Bhoo-Pathy N, Sothilingam S, Malek R, Sundram M, et al. Ethnicity is an independent determinant of age-specific PSA level: findings from a multiethnic Asian setting. PLoS ONE. 2014;9(8): e104917. https://doi.org/ 10.1371/journal.pone.0104917.

16. Mottet N, Bellmunt J, Bolla M, Briers E, Cumberbatch MG, De Santis M, Fossati N, Gross T, Henry AM, Joniau S, Lam TB, Mason MD, Matveev VB, Moldovan PC, van den Bergh RCN, Van den BroeckT, van der Poel HG, van der Kwast TH, Rouvière O, Schoots IG, Wiegel T, Cornford P. EAU-ESTROSIOG Guidelines on Prostate Cancer. Part 1: screening, diagnosis, and local treatment with curative intent. Eur Urol. 2017;71(4):618-29. https://doi. org/10.1016/j.eururo.2016.08.003.

17. Ahmed HU, El-Shater Bosaily A, Brown LC, Gabe R, Kaplan R, Parmar MK Collaco-Moraes Y, Ward K, Hindley RG, Freeman A, Kirkham AP, Oldroyd R, Parker C, Emberton M, PROMIS Study Group. Diagnostic accuracy of multi-parametric MRI and TRUS biopsy in prostate cancer (PROMIS): a paired validating confirmatory study. Lancet. 2017;389(10071):815-22. https://doi.org/10.1016/S0140-6736(16)32401-1.

\section{Publisher's Note}

Springer Nature remains neutral with regard to jurisdictional claims in published maps and institutional affiliations.

Ready to submit your research? Choose BMC and benefit from

- fast, convenient online submission

- thorough peer review by experienced researchers in your field

- rapid publication on acceptance

- support for research data, including large and complex data types

- gold Open Access which fosters wider collaboration and increased citations

- maximum visibility for your research: over 100M website views per year

At $\mathrm{BMC}$, research is always in progress.

Learn more biomedcentral.com/submissions 